\title{
ENTRE SIGNO E SIGNIFICANTE: A ESQUIZOFRENIA INCIPIENTE SEGUNDO CONRAD
}

Antônio Teixeira ${ }^{\star}$

\section{RESUMO}

Ao tratar da pesquisa empreendida por J. Conrad sobre a esquizofrenia incipiente, esse artigo demonstra a atualidade desse estudo: destaca-se a abordagem estrutural do desencadeamento psicótico ali inaugurada antes mesmo de Lacan estender a perspectiva estruturalista à fenomenologia da clínica. Enfatiza-se a estratégia utilizada por Conrad, que propõe pensar o desencadeamento psicótico nos termos da estrutura formal da percepção delirante. Demonstra-se em que sentido a perspectiva de Conrad resgata a inteligibilidade do fenômeno psicótico, opondo-se à estratégia da fenomenologia compreensiva fundada por Jaspers, a qual relegava ao plano somático da causalidade física os fenômenos mentais destituídos de compreensão.

Palavras-chave: Conrad. Esquizofrenia incipiente. Estrutura. Significação delirante.

\section{BETWEEN SIGN AND SIGNIFIER: THE INCIPIENT SCHIZOPHRENIA ACCORDING TO CONRAD}

\begin{abstract}
By dealing with Conrad's research on incipient schizophrenia, this article demonstrates the actual relevance of the study: it highlights the structural approach of psychotic crisis inaugurated by him, even before Lacan expands the structuralist perspective to the clinic's phenomenology. The author emphasizes the strategy employed by Conrad, who proposes to discuss the origins of psychotic crisis in terms of the formal structure of the delirious perception. He shows therefore the way Conrad's perspective is able to recover the intelligibility of the psychotic phenomenon, in opposition to the strategy of comprehensive phenomenology founded by Jaspers, which relegates to the somatic plan of physical causality the mental occurrences deprived of comprehension.

Keywords: Conrad. Incipient schizophrenia. Structure. Delirious meaning.

* Professor adjunto do Departamento de Psicologia da Faculdade de Filosofia e Ciências Humanas (Fafich) da UFMG.

Endereço: Rua Mata da Corda, 12, apto 3, Mangabeiras, Belo Horizonte - MG, CEP 3210-410. E-mail: amrteixeira@uol.com.br
\end{abstract}


Existe, para cada época, uma tendência em resgatar, do passado, doutrinas cuja atualidade o seu momento não soube alcançar. É como se necessitássemos, paradoxalmente, de uma espécie de retrospecção para vislumbrar o futuro, anacrônicos que somos, conforme formulara Gramsci, em nosso próprio tempo. Se julgo então pertinente resgatar Conrad, em nossos idos, é por me parecer que somente agora dispomos de condições para localizar a atualidade de seu estudo, o qual ainda permanece pouco conhecido tanto no meio psiquiátrico quanto no psicanalítico. Tal importância se deve ao fato de que ele inaugura, em sua abordagem da psicose, uma perspectiva em certos aspectos comparável, como tentarei demonstrar, a de um estruturalismo avant la lettre.

Conrad é o autor que lança uma luz original sobre o enigma da psicose, pela maneira com que procura abordar a esquizofrenia em sua forma incipiente. É no nível de uma crise de esquizofrenia, tão logo ela se desencadeia pela primeira vez, que Conrad vislumbra a possibilidade de examinar um fenômeno que a psiquiatria clássica havia deixado de lado, ao considerar a fenomenologia da psicose a partir do conceito jasperiano de processo. ${ }^{1}$

Como é sabido, ao qualificar de processual o início da esquizofrenia, a psiquiatria deixou de se ocupar com a sua inteligibilidade dessa transformação, afirmando tratar-se de uma causa física cuja natureza seria um dia desvelada pela ciência. Ao se contrapor a um tal niilismo epistemológico, Conrad tentaria examinar esse fenômeno a partir de uma ampla casuística de esquizofrenia incipiente, com a intenção de averiguar, nesse momento fecundo em que uma psicose se desencadeia, o tipo de estrutura que aí se pode localizar.

Se considero, portanto, K. Conrad como um estruturalista avant la lettre, é porque ele empreende seus estudos sobre a forma da significação delirante nos anos 1940 do século passado, ou seja, num momento em que a extensão clínica do estruturalismo ainda estava por se realizar. Faltava-lhe, em sua Gestaltanalyse do fenômeno esquizofrênico, o organon estruturalista do qual Lacan mais tarde iria se servir, falta essa que confere a seu esforço uma originalidade particularmente notável.

Qual será então o interesse de Conrad no tratamento dessa questão? Conrad vai examinar com a lupa mais de 140 casos de esquizofrenia, em seu estágio inicial, dando ênfase ao problema da crise e do desencadeamento, uma vez que é exatamente nesse período que se situa a fase propriamente processual da esquizofrenia, que a psicopatologia havia relegado ao plano somático. Vale, aliás, lembrar, retrocedendo a um período anterior, que o binômio crise-desencadeamento gozou de uma grande visibilidade no discurso médico até o início do século XIX, conforme observa Foucault (2002, p. 114) no texto "A casa dos loucos".

Foucault afirma, a propósito desse período, que o saber médico, então constituído, não dispunha, quanto a seu objeto, de uma permanência que lhe permitisse definir, de maneira estável, a natureza dos quadros mórbidos. A verdade da doença não aguardava o momento em que se realizava sua pesquisa; era preciso alcançála em sua própria eclosão. Era preciso captá-la no instante da crise, como se nesse 
momento a natureza da doença se exibisse e fosse dado ao médico encontrar aquilo que ele estava procurando. Havia, pois, uma tecnologia de produção da verdade da doença por meio da crise. A hospitalização, nesse sentido, servia como um lugar artificial para que se produzisse a eclosão dessa verdade, fazendo com que ela se revelasse em sua manifestação aguda.

Esse procedimento, prossegue Foucault, desapareceria somente com o surgimento da microbiologia de Pasteur, o qual, ao determinar o agente do mal físico da doença no organismo, mostraria que era possível demonstrar a verdade da doença - no caso, a sua etiologia - sem provocar a sua manifestação. Pasteur denunciava, além disso, que o médico, ao provocar a doença, era muito mais um transmissor ou um vetor para as infecções hospitalares do que um agente terapêutico (FOUCAULT, 2002, p. 120). Ele defendia a necessidade de se suprimir esse embate do médico com a doença, com vistas a fixar o campo epistêmico da medicina científica não mais no lugar da crise provocada, mas no espaço neutro de sua demonstração.

Curiosamente, a psiquiatria permaneceria guiada pelo modelo de provocação da verdade por um período consideravelmente mais longo do que a medicina. Ao passo que a clínica médica já lograva estabelecer, a partir do século XIX, demonstrações cada vez mais apuradas da etiologia dos processos mórbidos, com o avanço da microbiologia e da anatomia patológica, e a psiquiatria ainda insistia em suscitar a verdade da doença mental mediante técnicas cerimoniais de combate e provocação. Era patente a necessidade, escreve Foucault citando Esquirol, de "aplicar um método perturbador" com o fim de "subjugar o caráter de certos doentes" (FOUCAULT, 2002, p. 122). Continuava-se a aplicar os tratamentos concebidos à base de punições e recompensas, fazendo com que a representação da patologia mental dependesse da própria personalidade do médico alienista. Assim como o médico anterior a Pasteur era o elemento de propagação por contágio das doenças infecciosas, o alienista freqüentemente suscitava, por sua vez, as doenças de que ele deveria tratar. A histérica de Charcot, "verdadeira santidade epistemológica", no dizer de Foucault, reproduzia, em sua sugestibilidade mórbida, a maior parte das doenças mentais das quais se tinha conhecimento (FOUCAULT, 2002, p. 123).

Bayle merece, portanto, nossa homenagem, por ter sido o primeiro cientista que tentou demonstrar, a partir do exame histopatológico do cérebro dos pacientes, a causa corporal dos fenômenos mórbidos. Coube a ele desvelar a presença de um processo de aracnoidite crônica na doença então descrita como Paralisia Geral Progressiva (PGP) (BERCHERIE, 1989, p. 83-92). Por se empenhar nessa demonstração, Bayle terá sido o primeiro pesquisador a encontrar, no lugar do suspeito princípio de provocação da doença, o primeiro protocolo de demonstração científica das afecções mentais. Quando os trabalhos de Bayle, por quase 40 anos negligenciados, foram finalmente levados a sério, assistiu-se ao nascimento de uma psiquiatria de orientação científica, inspirada no desenvolvimento da patologia cerebral, que teve na Alemanha, nas figuras de Kaulbaum e de Kräpelin, seus principais expoentes. A partir de então, os médicos começaram a dissecar os cérebros dos pacientes que faleciam nos asilos, a fim de detectar o elemento 
demonstrável e não provocado da doença mental. E, no entanto, para nosso azar e para nossa sorte, duas patologias mentais de freqüência considerável, as ora chamadas demência precoce e loucura maníaco-depressiva, exibiam uma sintomatologia exuberante sem que se pudesse encontrar uma demonstração da etiologia na realidade física do corpo. Por mais que se examinassem o cérebro dos pacientes, nada de conclusivo era ali encontrado.

Foi diante desses impasses que a psicopatologia desenvolveu um método que permitisse abordar a natureza da doença mental, na ausência de uma demonstração da causa a partir da realidade física do corpo. A psiquiatria nascente buscou então se valer do procedimento epistemológico herdado de Dilthey, em sua concepção das assim chamadas ciências do espírito (Geistenwissenchäfte). Esse modelo lhe permitiria dispensar a explicação pela causa, valendo-se da compreensão do motivo da doença mental, ao considerar a relação entre a vivência historicamente determinada do paciente e o modo que nele se manifesta seu acometimento.

Realizou-se, assim, como é sabido, uma divisão epistemológica para reservar a explicação da causa como procedimento da ciência da natureza, propondo-se a compreensão do motivo enquanto procedimento das ciências hermenêuticas. $\mathrm{O}$ objeto dessa última deixa assim de ser a realidade física do corpo, ao colocar no seu lugar a realidade psicológica do sujeito histórico, do sujeito que tem a vida marcada por uma produção de sentido historicamente determinada. Se eu aqui resumo, ainda que toscamente, o modo pelo qual a psiquiatria integrou essa divisão epistemológica, é por ser no impasse dessa divisão que Conrad vai encontrar o motivo para propor seu estudo sobre a esquizofrenia incipiente.

Tínhamos, então, num período que percorre o século XIX, o desenvolvimento de duas disciplinas derivadas do assim chamado historicismo alemão: a fenomenologia de Husserl e a hermenêutica de Dilthey. Ambas integravam a segunda parte de uma divisão que iria opor, por um lado, as ciências da natureza, que procuram explicar a causa dos fenômenos físicos. E, por outro, as ciências do espírito, que visam compreender o motivo do acontecimento psicológico. Gerouse, assim, o dualismo epistemológico correspondente aos dois tipos de realidades assim pensadas de maneiras diferentes.

Podemos, aliás, dizer que a psicopatologia que herdamos, até hoje, se embasa nesse dualismo epistemológico. Se ela se organizou em torno do esforço clínico da compreensão ou procura da gênese psicológica dos fenômenos mentais, foi partindo da necessidade de se pesquisar os motivos e não mais a causa. Era preciso não somente uma valorização da história, mas também da relação empática entre o médico e seu paciente, para se averiguar se de fato um determinado tipo de comportamento era ou não psicologicamente compreensível. O que não podia ser captado no modelo genético da compreensão seria, portanto, retirado da abordagem psicológica do motivo, para ser considerado como um fenômeno somático, destituído de sentido histórico. Tal fenômeno passaria assim a ser tratado enquanto efeito de um processo físico postulado da realidade corporal, não mais passível de compreensão, mas de uma explicação que as ciências da natureza mais tarde descobririam. 
O interesse, portanto, do trabalho de Conrad, diz respeito ao modo de sua inserção crítica no domínio da psicopatologia, no período de coroamento dessa concepção organizada por K. Jaspers e retomada posteriormente por seu discípulo K. Schneider.

Parecia exorbitante, aos olhos de Conrad, considerar a série dos fenômenos presentes no desencadeamento da esquizofrenia - tais como a esquizoforia ou humor delirante, o falso reconhecimento, a percepção delirante, a difusão e a influência do pensamento - como um conjunto de fenômenos desprovidos de sentido (CONRAD, 1963, p. 29). Soava-lhe uma contradição absurda reunir todos esses fenômenos e em seguida recusar a atribuir-lhes qualquer sentido. Haveria, na postulação do processo, uma verdadeira demissão do pensamento, uma vez que por ela se aguarda a explicação posterior de uma causa física, ao mesmo tempo em que se renuncia a buscar a inteligibilidade do fenômeno em questão.

Qual seria então o sentido desses fenômenos? - pergunta-se Conrad, ao mesmo tempo em que se recusa a delegar ao plano somático a causa dos fenômenos presentes na esquizofrenia incipiente.

É bem verdade que já existia uma disciplina alternativa à psicopatologia de Jaspers quando Conrad escreveu seu livro. Essa disciplina alternativa era a antropologia existencial de Biswanger, de nítida inspiração heideggeriana, a qual buscava pensar a esquizofrenia não no âmbito do processo, ou seja, de uma causalidade física corporal, mas por meio de uma análise do projeto existencial do ser no mundo. A causa da doença mental se encontra ali identificada a um impedimento, ocasionado por fatores circunstanciais daquilo que seria o projeto existencial do Dasein, do ser no mundo do paciente.

Mas Conrad não se acomoda tampouco nessa alternativa. Parece-lhe inútil recorrer a uma tal antropologia existencial que, no fundo, revela-se uma epistemologia sem controle: a idéia mesma de uma interrupção do projeto existencial do sujeito encontra-se de tal modo relacionada a fatores circunstanciais que não se repetem que a teoria que dela se vale termina por se mostrar absolutamente carente de qualquer tipo de verificação. O que aconteceria ao sujeito, pergunta-se Conrad, acaso não houvesse ocorrido aquele acontecimento circunstancial que, ao bloquear seu projeto existencial, teria gerado a sua doença? (CONRAD, 1963, p. $13,30)$. Ora, o fato é que existem, prossegue Conrad, tantos projetos de ser no mundo de pacientes acometidos de esquizofrenia quanto existem esquizofrênicos. Não é, pois, possível pensar a esquizofrenia no âmbito de uma antropologia existencial, posto que não existe sequer a especificidade de um projeto do ser no mundo na esquizofrenia.

Quando Conrad escrevia seu livro, ele contava assim com duas alternativas:

- loucura $\Rightarrow$ plano somático ou infrapsíquico $\Rightarrow$ processo esquizofrênico;

- loucura $\Rightarrow$ plano existencial ou ultrapsíquico $\Rightarrow$ interrupção do projeto do ser no mundo do sujeito esquizofrênico. 
Conrad recusa ambas, dizendo que é preciso proceder a uma análise da vivência esquizofrênica mediante aquilo que ele denominou Gestaltanalyse, e que eu proporia traduzir como análise da configuração. Do mesmo modo, escreve Conrad, que se pode estudar uma música a partir da configuração estrutural de sua partitura, desconhecendo o projeto existencial que motivou seu compositor, eu posso e devo pensar o delírio do paciente em relação ao sistema em que esse delírio se encontra inserido, sem me ocupar com uma suposta interpretação do projeto existencial do ser no mundo.

Se me parece então plausível considerar Conrad um estruturalista avant la lettre, é na medida em que ele se propõe a desvelar a natureza do delírio na forma de sua inserção como sistema, independentemente do conteúdo particular de seus elementos, na mais estrita observância da abordagem estrutural dos fenômenos da cultura. Conrad procura então caracterizar o início da esquizofrenia, que se manifesta com uma elevação da tensão psíquica, relacionando-o à vivência, expressa pelo paciente, de que algo iminente vai lhe acontecer. A essa vivência, descrita por Jaspers com o termo pedante esquizoforia, Conrad dá o nome - extraído do jargão do teatro - de trema esquizofrênico, referido à sensação experimentada pelo ator logo antes de entrar pela primeira vez em cena (CONRAD, 1963, p. 47-62).

Algo vai acontecer, não há dúvida, mas o paciente, no início, não sabe o quê. Ele sabe somente que não é algo neutro; é sempre algo significativo que está para ocorrer. A expectativa desse algo se traduz num sentimento de estranheza: o paciente vive uma experiência de intensa indeterminação, que somente será resolvida quando a psicose desencadeia e surge uma percepção delirante em que o paciente diz "é isso": aquela corda pendurada na cortina é o sinal inequívoco de que vão me enforcar. Nesse "é isso", resolve-se a condição do trema, pondo de certo modo fim a sua angustiante experiência de indeterminação.

Se o processo aparece, então, em sua descrição fenomenológica, como uma fratura que interrompe a linha histórico-vital do sujeito, é na iminência dessa fratura que vamos encontrar o trema, o qual se resolve pela percepção delirante desse "é isso" que acomete o sujeito. A partir, portanto, do momento em que o "é isso" se produz, vê-se desencadear o fenômeno, descrito por Jaspers, como consciência anormal de significação, que passa então a se estender a todos os modos intencionais do paciente.

Cumpre lembrar, no entanto, que o conteúdo da percepção delirante em que se resolve o trema, embora diga incontestavelmente respeito à verdade da condição subjetiva do doente, adquire ali uma forma particular de manifestação. O paciente se vê diante de uma verdade que a ele se mostra não pela via dedutiva de uma inferência; trata-se antes de um fenômeno apofântico, de uma revelação. O "é isso" da percepção delirante é uma verdade revelada, e não deduzida (CONRAD, 1963, p. 63 et seq.).

Conrad, então, prossegue dizendo que essa revelação, que no início se dá no espaço externo do ambiente, estende-se progressivamente para o campo de sua percepção interna, instaurando o fenômeno de auto-referência ao qual ele dá o 
nome de anastrophé. A anastrophé seria, na descrição de Conrad, a vivência de um espasmo interpretativo, no qual o paciente passa a referir tudo o que ele percebe a relação a sua vivência interna. Tudo que se encontra no ambiente é um sinal a ser interpretado, como se o mundo estivesse imantado pelo pólo vivencial do sujeito. Aos poucos se desfaz então a continuidade de sentido, à medida que se dissolvem os elos nos quais os elementos do mundo encontravam-se originalmente interligados. Ocorre finalmente uma completa assintaxia, descrita por Conrad a propósito da fase apocalíptica, cujo exemplo clínico se encontra na experiência catatônica.

Qual seria, pois, a inteligibilidade do fenômeno em questão? A bem dizer, afirma Conrad, o fenômeno essencial já se apresenta desde a experiência da apofania. O enfermo ali se encontra preso no interior de um sistema sem transcendência, fora do espaço intersubjetivo, como se algo a ele se revelasse, mas somente a ele, intimamente, e a mais ninguém. ${ }^{2}$ Dito em outras palavras, o paciente psicótico tem a vivência de uma certeza sem transcendência; ele não consegue elucidar para ninguém a razão do "é isso" pelo qual se dá a sua verdade revelada.

Distintamente da verdade demonstrada, que é uma verdade encadeada, como no caso de um silogismo, em que a articulação de duas premissas confere a necessidade da conclusão, a verdade apofântica é uma verdade desligada da cadeia significante. Por esse motivo, propomos dizer que o "é isso" se revela no signo e não no significante. Quando se diz que o significante é o que representa o sujeito para um outro significante, supomos que o significante, como tal, nunca se apresenta isolado; ele sempre existe em relação aos demais, posto que não há significante fora da cadeia. Já o signo, por sua vez, é aquilo que se encontra fora da cadeia significante. O signo é, na verdade, um significante desencadeado, e é por se apresentar desencadeado que ele suscita a necessidade de se produzir, a seu redor, uma nova cadeia que lhe dê sentido, ou seja, uma interpretação. Para saber o que o signo quer dizer é necessário re-encadeá-lo numa nova cadeia significante. O delírio seria então uma tentativa de re-encadear um signo, de modo a que ele possa produzir um sentido para o sujeito. Ele engaja o sujeito nessa composição.

Afirmamos, portanto, que o sujeito procura o signo quando se encontra diante de uma verdade que ele suspeita existir de forma não articulada na cadeia significante. É por isso que o ciumento é ávido por signos: ele pressente uma verdade não encadeada numa declaração significante, como bem sabia o sórdido personagem de Iago, da peça Otelo, de Shakespeare, ao fazer surgir o lenço de Desdêmona nos aposentos de Cássio. Mas vale lembrar, junto a Lacan, que a fumaça não é necessariamente signo do fogo, ela pode antes ser signo do fumante. E que quem cala nem sempre consente, o silêncio é muitas vezes signo do não. Ou seja: o valor do signo não é nem de longe unívoco, ele só significa se veiculado a uma cadeia que cada sujeito em torno dele compõe.

Na vivência apofântica descrita por Conrad, o sujeito se encontra diante de um signo que toma a forma, descrita por Lacan, de uma intuição plena sobre a qual irá se tecer a interpretação delirante. Ele se encontra inundado pela certeza de que esse signo lhe concerne, sem que seu valor possa lhe ser dado de antemão. 
Por isso Lacan distingue dois pólos fenomênicos relacionados à certeza delirante. Por um lado, temos uma fórmula plena, em razão do aspecto transbordante que ela tem para o sujeito concernido. Por outro, trata-se de uma fórmula vazia em que o "é isso" não remete a nada mais além dele próprio, na forma de uma cadeia quebrada (LACAN, 1981, p. 43-44).

Se voltarmos agora à explicação de Conrad (CONRAD, 1963, p. 80), o que se encontra subjacente ao aspecto apofântico da certeza delirante é que um traço do objeto percebido se converte, para o enfermo, na própria essência da significação. E como se houvesse nos objetos uma nuvem de propriedades essenciais que se liberam no delírio, escreve Conrad, valendo-se de uma imagem que nos evoca claramente o enxame de S1 de que nos fala Lacan em Encore (LACAN, 1975, p. 130).

Já na vivência dita normal, há algo que encadeia previamente a percepção, separando os aspectos essenciais daqueles que não o são. Ninguém aqui presente - supondo-se que nenhum de nós nesse instante delira - presta atenção na cor verde do quadro negro, ou na cor amarelada do giz branco que eu pedi. $\mathrm{O}$ que se dá, por outro lado, no caso do paciente esquizofrênico, é uma espécie de inundação de signos, um excesso de informações. Falta-lhe um filtro para separar o essencial do irrelevante, no sentido em que o esquizofrênico padece, para usar um termo caro às assim chamadas neurociências, de uma desregulação do mecanismo de input.

Mas é importante lembrar, e aqui eu me separo dos representantes das neurociências, que o que faz funcionar o filtro do input na consciência, longe de ser um dado natural ou biologicamente determinado, é antes a amarração da linguagem pelo dado social ou cultural do discurso. O discurso no qual eu estou inserido é aquilo por meio do qual se define o essencial e o irrelevante.

Existe na percepção dita normal das coisas, conforme já notara claramente Merleau-Ponty (1945), em Fenomenologia da percepção, a necessidade de jogar certos elementos no campo indeterminado que faz a borda da visibilidade, para encadear outros no campo de enfoque da observação. ${ }^{3}$

Quando Conrad então afirma que, na experiência apofântica, desprende-se, do objeto visado, "uma nuvem de qualidades essenciais", o que na realidade se libera são elementos que, por deixarem de estar encadeados na rede do discurso, passam a funcionar como signos ávidos de interpretação. Sabemos, aliás, que quanto mais encadeada se apresenta a fala do paciente, mais preservada se encontra sua condição clínica. Por isso, esperamos um melhor prognóstico nos pacientes com delírios fortemente sistematizados, e um pior prognóstico nos casos de maior profusão de signos ou de elementos desencadeados, como se verifica no exemplo extremo da experiência catatônica.

A propósito ainda da fenomenologia da percepção, vale lembrar que o ato perceptivo opera mediante uma seleção de elementos que se encontram no campo exterior, fazendo com que a percepção seja recolhida numa formação ligada a um conjunto em que o elemento percebido será ordenado. A unidade do objeto perce- 
bido se funda, segundo Merleau-Ponty, sobre o pressentimento de uma ordem iminente. Ela não é uma somatória dos elementos: eu não percebo a cor da pele, depois a roupa preta, em seguida o branco dos olhos e movimento dos cabelos para compor uma pessoa; a unidade da coisa é dada antes, a percepção já instaura a unidade que ela mesma desvela. A percepção é, pois, uma interpretação de sinais que a sensibilidade fornece a partir de uma hipótese que o espírito cria para explicar sua sensação. Ela não somente descobre os sentidos que o objeto percebido tem, como faz com que esse objeto tenha um sentido (MERLEAU-PONTY, 1945, p. 40-46).

Mas se a coisa percebida é sempre percebida num determinado lugar, a percepção que percebe não se encontra, ela mesma, fixada em algum lugar do campo perceptivo. A percepção é uma percepção dirigida a elementos relacionados entre as coisas. O campo perceptivo é sempre um campo de relações, no qual está invariavelmente presente uma zona de apagamento. É necessário que haja, na percepção, um halo de indeterminação do qual se destaca a experiência do visível.

Se, pois, por um lado, a esse halo de indeterminação que envolve a percepção corresponde o que chamamos de mundo, por outro lado, a crença de que, sobre esse campo indeterminado, a percepção sempre se organize vem a ser o que Merleau-Ponty nomeia preconceito do mundo (préjugé du monde) (MERLEAUPONTY, 1945, p. 65). Preconceito no sentido em que a percepção é sempre um julgamento, uma interpretação que ignora as suas razões (MERLEAU-PONTY, 1945, p. 55). Ela se move num campo indeterminado que ela própria não percebe. Posso me iludir, enganar-me em relação ao que eu percebo, mas eu não sou psicótico porque disponho sempre desse preconceito de que há um mundo sobre o qual minha percepção se organiza. O que surge assim no lugar dessa crença que MerleauPonty chama de preconceito do mundo, sobre o qual a percepção encontra sua estabilidade, nada mais é do que aquilo a que Lacan dá o nome de discurso. É pelo discurso que minha percepção se encadeia e se realiza como percepção compartilhada num campo de mediação dialética. O discurso é justamente o que instaura o campo de mediação do fenômeno perceptivo.

Quando Conrad, ao falar do humor delirante e da vivência apofântica, refere-se a uma perda da realidade, a realidade que ali se perde é a possibilidade que tinha o sujeito de pertencer a esse campo de mediação. O sentimento de desconfiança da fase apofântica se relaciona, pois, à vivência, expressa pelo paciente, de que nada mais é natural, nada mais é compreensível por si mesmo. Pois o que na realidade falta, para o sujeito psicótico, é justamente o preconceito do mundo que forma, em sua neutralidade indeterminada, o transfundo da percepção. Nada mais é neutro, nada mais é indeterminado: tudo é virtualmente signo, tudo tem vocação para significar, tudo é potencialmente significante.

O transfundo perde a sua neutralidade e se enche, portanto, de propriedades complementares. Por isso, no êxtase perceptivo de um paciente delirante, o transfundo passa a ter uma relevância que normalmente ela não teria. $\mathrm{O}$ sujeito delirante se transforma, a partir da experiência do desencadeamento, num sujeito constantemente à espreita de signos a serem interpretados, com o caráter 
fundamental de que, nessa interpretação, o enfermo padece da incapacidade, descrita por Conrad, de mudar de sistema de significação, de pensar aquilo que ele pensa segundo outra maneira.

Por isso, Lacan vai dizer da inércia dialética como um dado patognomônico da experiência psicótica (LACAN, 1981, p. 32). O sujeito imerso em sua certeza é incapaz de elaborar uma composição dialética daquilo que ele percebe, como verdade; ele é incapaz de tomar a sua posição e comparar com a posição de um outro sujeito e encontrar o meio termo. É o paciente imerso numa certeza sem composição dialética porque ele não dispõe do preconceito do mundo que seria o espaço de mediação onde uma nova concepção poderia se realizar.

\section{Notas}

1 Cf. JASPERS (1985), ver sobretudo terceira parte do v. II: As conexões causais da vida psíquica.

2 “[...] tal 'transcendência' ya no le es posible al enfermo delirante. Precisamente en esto radica la esencia del delírio." (p. 62).

3 "Il nous faut reconnaître l'indéterminé comme un phénomène positif". Cf. MERLEAU-PONTY, La phénoménologie de la perception, Paris, Gallimard, 1945, p. 12. Cf. igualmente o capítulo: "Le champ phénomenal", p. 64-77.

\section{REFERÊNCIAS}

BERCHERIE, P. Os fundamentos da clínica: história e estrutura do saber psiquiátrico. Rio de Janeiro: J. Zahar, 1989.

CONRAD, K. La esquizofrenia incipiente: intento de un análisis de la forma del delírio. Madrid: Alhambra, 1963.

FOUCAULT, M. A casa dos loucos. In: . Microfísica do poder. Rio de Janeiro: Graal, 2002.

JASPERS, K. Psicopatologia geral. Rio de Janeiro: Atheneu, 1985.

LACAN, J. Le séminaire: encore. Paris, Seuil, 1975. Livre XX. Le séminaire: les psychoses. Paris: Seuil, 1981. Livre III.

MERLEAU-PONTY, M. La phénoménologie de la perception. Paris: Gallimard, 1945.

Recebido em: março/2005

Aceito em: março/2006 